\title{
Family out-of-home eating in times of economic stress; an exploration of parental behaviour and attitudes
}

\author{
R. K. Price, L. McGuffin, J. M. W. Wallace, T. A. McCrorie and M. B. E. Livingstone \\ Northern Ireland Centre for Food and Health (NICHE), University of Ulster, School of Biomedical Science, \\ Coleraine BT52 ISA, UK
}

The sustained economic contraction since 2008 across both the UK and Ireland may impact on health as many studies report increased obesity rates in times of economic stress ${ }^{(1)}$. Out-of-home eating may have a role to play as foods eaten out-of-home tend to be associated with higher energy and fat intakes ${ }^{(2)}$. The aim of this work is to explore recession-related factors influencing parental behaviour and attitudes while eating out-of-home.

Twenty-four focus groups (7-8 parents, 60-90 mins/group) were conducted across the island of Ireland during the summer of 2011. Purposive sampling techniques were used to ensure parents recruited represented a range of demographic (North, South; rural, urban) and socioeconomic backgrounds as well as age of parent and child (5-12 years). Group sessions were audio-recorded, transcribed and analysed using a thematic approach.

Results indicated that economic stress was driving a change in parental behaviour and attitudes while eating out-of-home. Parents reported changing the eating-out location in favour of reducing the number of eating-out occasions (Table 1). Fast food outlets, takeaways, meal deals and 'early birds'/lunches had become more popular eating-out venues. In addition parents discussed strategies to cut costs to maintain eating-out frequency including, only ordering water or diluting juice, stopping on the way home for dessert, or carrying food home to avoid inevitable additional costs such as desserts and alcoholic/soft drinks. Eating out was considered a 'treat' and thus it was very important to parents that they received 'value for money' and avoided food wastage when using their limited resources (Table 1). Parents discussed strategies to ensure their child received a meal that they 'would eat' and would 'fill them up' to avoid the additional cost of re-feeding the child once home.

Table 1. Recession-related themes, sub-themes and quotes from focus groups investigating parental behaviour and attitudes while eating-out of the home.

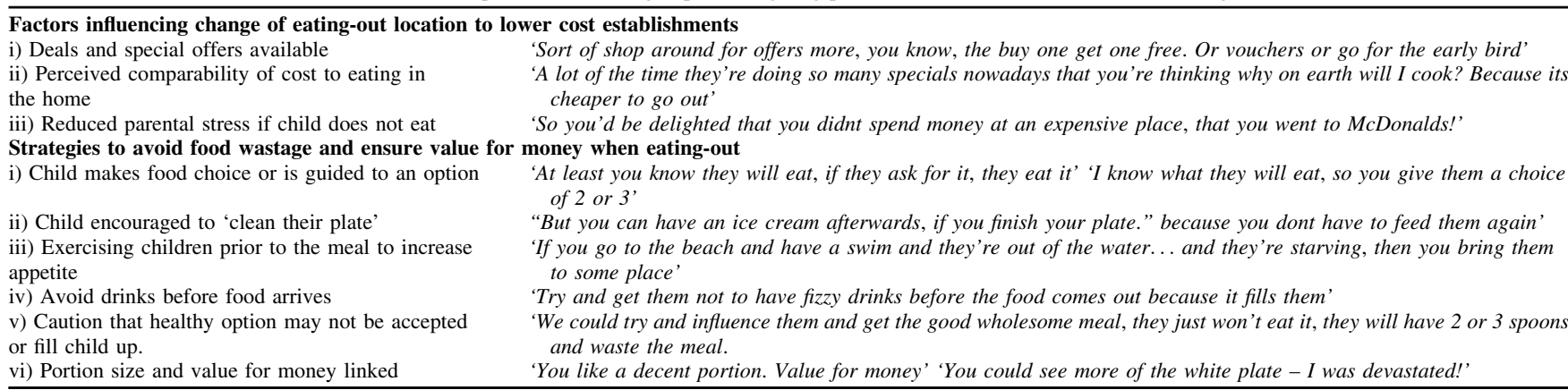

These findings show that, irrespective of socioeconomic status or location, parental behaviour and attitudes while eating-out-of-home are changing as a result of the recession and that priorities of 'value for money' and 'reducing food wastage' overshadow nutritional considerations. This work highlights a challenge for health professionals to ensure that nutrition communications resonate with consumers in times of economic stress.

This material is based upon works supported by safefood, the Food Safety Promotion Board, under Grant No. 10-2009.

1. Scheier LM. (2005) J Am Diet Assoc 105, 883-886.

2. Lachat C, Nago E, Verstraeten R et al. (2011) Obes Rev. DOI: 10.1111/j.1467-789X.2011.00953.x. 